\title{
GENOMA Y BIOÉTICA: UNA VISIÓN HOLÍSTICA DE CÓMO VAMOS HACIA EL MUNDO FELIZ QUE NOS PROMETEN LAS BIOCIENCIAS
}

\author{
Jean-Luc M.J. Antoine*
}

\begin{abstract}
Resumen: La idea de la ciudad utópica es casi tan antigua como el pensamiento humano. Ella consiste en una sociedad teóricamente perfecta y transparente donde todo está perfectamente controlado y, en consecuencia, los ciudadanos podrían alcanzar la felicidad.

En este artículo pretendemos reflexionar, mediante una perspectiva holística -y con ejemplos prácticos como la clonación, células troncales y eugenismo-, acerca de la sociedad genética actualmente en ciernes, la que, a pesar de presentarse como una potente herramienta para alcanzar una ciudad utópica, sería hoy imposible por los numerosos riesgos y peligros existentes. Por tanto, creemos importante un análisis sobre la bioética y el progreso, antes de seguir adelante.
\end{abstract}

Palabras clave: Genética, bioética, clonación, eugenesia, células troncales

\section{GENOME AND BIOETHICS: AN HOLLISTIC VISION OF THE WAY WE MARCH TOWARDS THE HAPPY WORLD BIOSCIENCES PROMISE}

\begin{abstract}
The idea of an utopian city is almost as old as human thinking. It consists in a society theoretically perfect and transparent where everything is under control, so that citizens could achieve happiness.

In this article, using a historical perspective, we pretend to reflect, with practical examples such as cloning, stem cells and eugenics, on a genetic society which is blossoming and in spite of presenting itself as a strong tool to achieve the utopian city, this would not be possible due to the warning for many risks and dangers. Therefore we believe it is important to carry out an analysis on bioethics and progress, before moving on.
\end{abstract}

Key Words: Genetics, bioethics, cloning, eugenics, stem cells

\section{GENOMA E BIOÉTICA: UMA VISÃO HOLÍSTICA PARA O MUNDO FELIZ QUE NOS PROMETE AS BIOCIÊNCIAS}

Resumo: A idéia da cidade utópica é quase tão antiga como o pensamento humano. Consiste numa sociedade teoricamente perfeita e transparente onde tudo está perfeitamente controlado, onde consequentemente os cidadãos poderiam alcançar a felicidade. Neste artigo pretendemos refletir, mediante uma perspectiva holística -e com exemplos práticos como a clonagem, células tronco e eugenismo-, acerca da sociedade genética atualmente em cernes, a que, apesar de apresentarse como uma potente ferramenta para alcançar uma cidade utópica, hoje seria impossível pelos numerosos riscos e perigos existentes. Portanto, cremos que é importante e necessário fazer uma análise sobre a bioética e o progresso, antes de seguir enfrente.

Palavras-chave: Genética, bioética, clonagem, eugenesia, células tronco

Doctor en Genética Humana

Correspondencia: jeanluc368@yahoo.fr 
"Pensad por cuenta propia y dejad que los demás disfruten del derecho a hacer lo mismo."

\section{Francois Marie Arouet Voltaire}

\section{Introducción: la ciudad utópica}

La genómica y la proteómica son neologismos de reciente creación que aumentan la lista de las nuevas siglas y técnicas bárbaras que son puestas a disposición de todos, y que han entrado con fuerza en nuestras mentalidades, culturas, discursos y vocabularios. Es hoy común afirmar que las últimas aplicaciones de la genética van a afectar la intimidad de nuestras vidas y que constituirán los fundamentos de una nueva sociedad: el último avatar del mito secular de la ciudad utópica.

Sin embargo, estos nuevos logos y las miríadas de siglas, tales como FIV, MBE o PCR, son también símbolos de un cisma creciente en el seno de la nueva sociedad, la cual tiende a dividirse entre "los que saben" y "los que no saben", entre los "nuevos cultos" y los "nuevos ignorantes". El distanciamiento social así creado en la aldea global(1) está por generar nuevas castas de individuos (los gobernantes y los gobernados, los poseedores y los desprovistos, los privilegiados y los ignorados) dentro de un sistema que va mucho más allá del simple uso de nuevas técnicas y tecnologías y que está bajo el gran control de los mercados y de sus iniciados. La nueva Babel tiene el gran riesgo intrínseco de distanciar más aún a los ciudadanos, en lugar de englobarlos en una supersociedad basada en la idea de una nueva democracia fundada sobre la ecuanimidad, la igualdad de oportunidades, los derechos a la dignidad y a la felicidad. La gran profusión de conocimientos y descubrimientos, así como de las tecnologías que derivan de ellos, todos encauzados por el "gran capital global" y por los políticos fieles o resignados al mando vertical de este último, están generando nuevas capas sociales transversales a nivel planetario, las cuales vienen a adicionarse a las verticales ya existentes en cada país, cada región, cada cultura, cada religión. La utopía de Tomás Moro está tomando cuerpo en un mundo global que tiende a perder sus ideales democráticos $\mathrm{y}$, sobre todo, sus ideales de felicidad.

La utopía es una técnica de gestión social de los hombres, ubicada bajo el signo de la razón. La ciudad utópica, que debería ser totalmente transparente, está dando lugar, más bien, a una aterradora transparencia del individuo. En efecto, la medicina predictiva, por ejemplo, bajo la presión de las aseguradoras o de los empleadores, podría permitir que información sobre nuestra salud y nuestro posible destino médico esté a disposición de terceros.

Ligado de cerca a lo anterior, se encuentra el valor moral que tiene y tendrá la ideación y la concreción de la nueva ciudad global: ¿bajo qué términos éticos estamos construyendo el futuro de nuestras proles? "La felicidad para todos" es el lema que aparece en todas las discusiones sobre el tema, pero tenemos muchos ejemplos históricos de nuevas tecnologías que sirvieron más a la destrucción que a la felicidad. Es más: ¿quién determina las bases éticas, legales y políticas del uso de tales o cuales tecnologías? Son aquellos que pertenecen a esa casta de "los que saben" y que dentro de sus centros, escuelas, universidades, capillas y templos determinan lo "bueno" y lo "malo" basados en ideas varias y, a veces, muy discutibles acerca de la felicidad para todos.

La utopía clásica nace en el siglo XVI con las convulsiones intelectuales ocasionadas en Occidente por el descubrimiento de América y el consiguiente choque cultural que éste ocasionó. La utopía emerge en el oscurantismo de la Edad Media, y no es casual el sorprendente paralelismo que se bosqueja entre ese sombrío 
pasado y la ciudad utópica que se está levantando sobre la base de un diseño vertical de mando, de castas intelectuales, culturales y socioeconómicas, alentada por la moral pensada desde arriba en aras de un mundo mejor, un mundo justo, un mundo feliz para todos.

\section{La genómica y sus productos benefactores en la ciudad utópica}

En este capítulo trataremos algunos ejemplos de aplicaciones directas y controversiales acerca de los productos biomédicos de la genómica, después de recordar, brevemente, cuál es el concepto de genómica, con el propósito de poner sobre el tapete el debate y los interrogantes bioéticos que dichas aplicaciones implican.

\section{La genómica como ciencia}

El neologismo "genómica" se refiere a la ciencia del desciframiento del genoma, ya sea humano o de otras especies. El genoma humano es el conjunto de genes que determinan lo que somos biológicamente y -tal vez en parteintelectualmente. Ese conjunto tiene una base química llamada ADN (ácido desoxirribonucleico) que se encuentra dentro del núcleo (karion) de cada una de las células que componen tejidos, órganos y organismos, y que está compuesto de un alfabeto de cuatro bases elementales ordenadas según esquemas muy complejos. Esas cuatro bases están organizadas en 23 pares de cromosomas independientes al interior del núcleo celular y componen el alfabeto de unas frases equivalentes a 3.000 millones de letras, las cuales corresponden, luego de varias "traducciones" y "manipulaciones" bioquímicas, a algunas decenas de miles de genes (algunos pretenden que son algunos miles) que determinan los caracteres y sus sistemas de funcionamiento y regulación (por ejemplo, el color de los ojos, el metabolismo del azúcar, la estatura, entre otros). Un gen puede determinar un solo carácter o intervenir en varios de ellos, y un carácter puede derivar de la acción de un solo gen o de varios, la mayoría de ellos siendo multigénicos. Es más, un juego de genes o un gen aislado puede expresarse en un momento y en un lugar dado y no en otro, así como algunos se expresan en un tipo de células y no en otro y viceversa; esto permite que exista la "diferenciación celular", vale decir: esto hace la diferencia entre una célula del hígado y una célula de la piel, pese a que ambas contienen el mismo ADN en cantidad y en calidad. Ahí radica la dificultad de dilucidar el funcionamiento de nuestro genoma.

Entre todos los individuos que pueblan la tierra, se considera que existe una similitud exacta de $99,9 \%$ de todos los genes del genoma, el $0,1 \%$ restante hace que seamos distintos uno del otro. Tenemos apenas el doble de genes que una mosca del vinagre (drosofila melanogaster) y existen animales que tienen mucho más que los humanos; la diferencia evolutiva reside en cómo se relacionan y funcionan dichos genes. Un gen o un grupo de genes alterados pueden promover una enfermedad y, de hecho, la mayoría de las patologías tienen una base genética (por ejemplo, el cáncer, la esquizofrenia o la diabetes). Es preciso mencionar que, en este nivel, "genético" no significa "hereditario", pues para que así sea debe existir una alteración génica en las células germinales (reproductivas).

Tenemos la convicción de que muchos genes -si no todos-son "inductibles", es decir, están presentes en el genoma, pero requieren de fuerzas exteriores (tales como el medio ambiente, la educación, la psicología, la presión social, entre otras) para expresarse. Muchas enfermedades se explican, desde ya, por la influencia del medio ambiente (mutaciones e inducciones), y se descubre cada día que varias conduc- 
tas psicológicas - hasta sociales-encuentran su explicación en esta aseveración.

Lo que hoy sabemos representa sólo palabras escritas en un millón de páginas, con relaciones horizontales e hipervínculos entre ellas, sin que sepamos lo que significan realmente. Hasta el momento se identificaron menos de 2.000 genes relacionados con 1.500 a 1.800 enfermedades humanas. Faltan por lo menos veinte años, según las predicciones, para conocer el funcionamiento de todos los genes, ya que se debe estudiar en profundidad sus productos primarios (las proteínas) a través de la nueva ciencia que se llama "proteómica". Finalmente, es preciso mencionar que, pese al desconocimiento del funcionamiento y de la regulación génica, existen muchos marcadores que admiten, desde ya, establecer probabilidades acerca de la ocurrencia de enfermedades, hecho que permite tanto la prevención de su aparición, como el peligroso control preocupacional por parte de las empresas o de las aseguradoras.

\section{Algunos ejemplos elegidos y controversiales de los productos biomédicos de la genómica}

\section{La clonación humana, el uso de embriones y de células troncales}

El hombre occidental tiende a buscar la inmortalidad. Pese a su inexorabilidad, él sigue buscando vías para vivir más y mejor, "rejuvenecer" y, sobre todo, no morir. Entre el "morir bien" o eutanasia -en cuyo debate no entraremos por ser irrelevante en este artículo-y el no morir, el occidental demuestra un temor a la muerte, a lo desconocido, a la pérdida de sus bienes, cuerpo e identidad, como ser humano y ser social. No ocurre así en las civilizaciones orientales cuyas filosofías de vida son muy distintas.

La clonación (también llamada "transferencia nuclear" o reproducción exacta -teórica- mente- de un individuo a partir de la introducción de un núcleo celular somático - piel, por ejemplo- en el óvulo enucleado de una mujer $\mathrm{y}$, después, de dicho producto en el útero de la misma) permite llegar a la obtención de un ser idéntico al donante del núcleo. Teóricamente -de nuevo- el proceso se puede repetir de manera indefinida y obtener, de ese modo, colonias de clones de la misma persona. En un nivel técnico, el cigoto clonal y las células descendientes de este último no pueden ser todavía las fotocopias exactas de la célula donante de núcleo, dada la influencia de otros factores, tales como el ADN mitocondrial del óvulo enucleado receptor que proviene de la mujer donante y otros agentes citoplásmicos y proteicos. Sin embargo, podemos considerar que los avances de la tecnociencia permitirán, con relativa rapidez, llegar a resolver ese tipo de problemas, lastimosamente a través de la misma clonación. Otro problema biológico reside en que, para obtener un solo clon, debe sacrificarse una gran cantidad de fetos así producidos. Esto presenta un gran problema ético, puesto que se está jugando con la suerte de muchas vidas humanas en pos de obtener un "producto" particular.

Además de los problemas y de los peligros técnicos aparecen muchos interrogantes éticos. Varios de ellos, que serán descritos en páginas ulteriores, toman en consideración problemas y litigios específicos de la bioética y de los sistemas humanos. Sin embargo, no tenemos respuestas aún acerca de la validez de la clonación de seres humanos. Sus panegiristas más entusiastas apuntan a la inmortalidad del hombre a partir de su exacta reproducción (raelistas); otros aseveran que no estamos frente a un problema ético sino médico, que permitirá a personas estériles tener sus propios hijos a través de la doble técnica clonación-fecundación in vitro (Antinori y Zavos); R. Seed afirma que la clonación permitirá llegar a tener los 
conocimientos necesarios para frenar el envejecimiento y, tal vez, revertirlo, así como estudiar la influencia del ADN mitocondrial en la senectud celular.

Es cierto que existen opciones muy prometedoras en cuanto a salud y calidad de vida: un infarto cardíaco podría ser tratado y eliminado gracias a la clonación de las células del mismo corazón que reemplazarían a las lesionadas. En el mismo orden de ideas, la clonación de tejidos y órganos permitiría tener bancos personalizados de material de reemplazo totalmente inmunocompatibles en caso de enfermedad o destrucción. De ahí a solucionar todos los problemas de injertos de órganos y tejidos falta poco; pero $¿$ es preciso llegar a clonar un individuo entero para guardarlo en un banco de material biológico en caso de que sea necesario injertar al "original"? Sin contar con que el "original", inmortal y "reparable" a voluntad, podría caer fácilmente en un sistema de vida totalmente descontrolado (fumar y beber sin límite, drogarse, contraer y difundir enfermedades, por ejemplo) sin necesidad de creer en cualquier tipo de existencia moral.

Por otro lado, podrían, también, para evitar esas conductas anárquicas, generarse terribles tiranías totalitaristas y represivas. Todo esto podría conducir a otro tipo de caos: es otra visión posible de la ciudad utópica.

Otros problemas éticos esenciales surgen a un nivel social y espiritual: ¿será el clon un ciudadano de idéntico "nivel" que el original, con los mismos derechos y deberes? ¿O un individuo de segunda categoría, apto para enviar a explorar otros mundos, trabajar en condiciones peligrosas y servir a los "originales"? En ese caso, no sería tan "grave" su pérdida, pues sería "material desechable y directamente reemplazable a bajo costo". Ahí surge el tema de la fuerza que puede ejercer el sistema económico sobre las decisiones éticas y políticas, el cual será considerado más adelante. ¿Tendrán esos "seres" un alma? ¿Serán iguales ante Dios, ante los creyentes, ante la metafísica? Lo cierto es que si un día logran llegar a ser biológicamente idénticos, nunca lo serán como individuos propiamente dichos, pues existen muchas variables ambientales, educacionales, psicológicas, sociales y espirituales que no pueden ajustarse. El problema espiritual nunca podrá ser resuelto y esto representa una condicionante ética de gran peso.

Otro asunto ligado muy de cerca a la clonación es el de las células troncales o células madre (stem cells). Se trata de células embrionarias -en gran mayoría- de muy temprana edad (antes de la implantación intrauterina, a un nivel de desarrollo llamado "blastocisto"). Esas células son pluripotenciales, vale decir, son capaces, naturalmente, de transformarse y reemplazar a cualquier tipo de las 200 variedades de células del organismo humano. Su origen es el embrión, "original" o clonado. Si bien es cierto que las esperanzas terapéuticas del uso de dichas células son enormes -reemplazo o corrección de órganos y tejidos, terapia celular en numerosas enfermedades (diabetes, Parkinson, lesiones medulares, entre otras)-, también despiertan problemas bioéticos importantes. El principal consiste en saber si estamos usando simples células o bien si se trata de seres humanos vivos en potencia.

Existe un debate casi imposible de resolver acerca de la existencia de una persona humana (real o potencial) a ese nivel de desarrollo embrionario. La Iglesia Católica Romana, a través de su autoridad espiritual superior, ha decretado, basada en numerosas reflexiones y asesorías, que la vida existe en el momento de la fecundación. Otros dicen que sin el doble evento fecundación-implantación no existe vida. El pensador utilitarista australiano Peter Singer, 
en entrevista al diario "Las Últimas Noticias" -Santiago de Chile 1 de septiembre de 2004, página 4-, argumenta: “¿Cuándo comienza la vida? Es la pregunta equivocada [...] no creo que haya ninguna significación moral en ello [...] no debemos preguntarnos cuándo comienza la vida, sino en qué minuto la vida adquiere un estatus que hace que el acabar con ella sea intrínsecamente algo malo". También se debe considerar la noción de persona y de conciencia: ¿cuándo existe la persona? ¿Existe en un "montículo" de células sin sistema nervioso, sin órganos, sin cerebro, o se considera solamente como persona "en devenir"? ¿Tiene alma el blastocisto? Las mismas preguntas se pueden plantear en relación con la conciencia, imperativa en la existencia de la persona como tal. Todas las grandes religiones promueven el respeto a la vida, pero también apoyan el derecho humano a vivir sana y dignamente. ¿Debe la ética orientarse a salvaguardar el derecho a la felicidad y a la dignidad de la mayoría o de todos? $\mathrm{O}$ ¿debe la ética salvaguardar a cualquier precio la idea de vida, la esencia divina de la vida, aunque sea en potencia? Podríamos llegar a lo que muchos considerarían como absurdo: ¿hay vida humana, persona y alma en devenir en las células germinales? Aunque no hayan pasado por la fecundación y cuenten con la mitad del lote cromosómico, también son vidas potenciales. ¿Qué pasa, entonces, con la natural destrucción de la gran mayoría de ellas? ¿Qué pasa con el tema de la polución nocturna y del onanismo masculino, con el de las relaciones sexuales sin afán reproductivo $\mathrm{o}$, simplemente, que no llegan a la fertilización?

\section{El eugenismo y el diseño del "homo geneticus"}

Eugenismo (del griego eu, bien, y gennân, nacimiento) significa literalmente "bien nacer". El eugenismo es una técnica que busca mejorar a la sociedad humana según los conocimien- tos en la materia. Hoy dicha técnica se basa en la genética.

Existen dos tipos de eugenismos. El "eugenismo pasivo" trata, esencialmente, de la elección natural que aparece siempre en el momento de optar por rasgos genéticos útiles para la supervivencia de la especie. La mayoría de los animales de sangre caliente de ambos sexos buscan la "mejor" pareja. Una forma muy liviana sería la elección de un cónyuge. Ese tipo de eugenismo no está controvertido, pero sí el "eugenismo activo", que es mucho más discutible.

El eugenismo existe desde los tiempos más remotos, pero el moderno nace con Francis Galton (1822-1911), psicólogo y fisiólogo inglés, primo de Charles Darwin y pensador victoriano muy adinerado. El es inventor del vocablo (eugenics) -aunque también utilizó el término "viricultura"-, a raíz del cual fundó la Galton Chair of Eugenics en el University College de Londres ${ }^{1}$. Su formulación del eugenismo se basa en la búsqueda del mejoramiento de las reservas (stock) humanas y en prevenir el deterioro del potencial genético del hombre $(2)^{2}$. La noción de eugenismo se popularizó rápidamente entre los científicos e intelectuales de su época. Su trabajo culminó en la búsqueda del mejoramiento racial (race improvement) como eugenismo(3). Sin embargo, Galton no conocía los trabajos de Gregor Mendel acerca de la transmisión de los caracteres hereditarios y no podía distinguir entre, por una parte, el mejoramiento genético de los humanos por selección de los caracteres hereditarios estimados como deseables y/o la su-

Para más información, consultar [Sitio en Internet] Disponible en http://www.galton.org

2 Ver: Galton F. Eugenics: its Definition, Scope and Aims. American Journal of Sociology 1904; X(1). En esta publicación se presenta, asimismo, un interesante debate entre Galton, G.B. Shaw, H.G. Wells, entre otros, acerca del eugenismo. 
presión de caracteres estimados como indeseables, y, por otra, el mejoramiento de los individuos a través de intervenciones acerca de sus condiciones de vida. Él se inspiró directamente en los trabajos y las enseñanzas de Darwin, muy influenciado por Malthus. En breve descripción, los principios del eugenismo de Galton se basan en el concepto de compensación de la pérdida de los mecanismos de selección natural.

Las leyes del eugenismo de Galton han sido ampliamente debatidas y discutidas y han inspirado a un gran número de filósofos y pensadores. También han sido tergiversadas a lo largo del siglo XX, en particular por los nacionalsocialistas desde 1933. La nueva "versión" del eugenismo nazi consistía en favorecer la fecundidad de los humanos considerados como superiores (política pronatalista, apoyo familiar, por ejemplo) y, a la vez, prevenir la reproducción de los humanos considerados como inferiores o bien no deseables a nivel eugénico (los criminales, homosexuales, entre otros). No hubo que esperar que Hitler llegase al poder para que una mayoría de políticos alemanes fueran favorables a ese tipo de eugenismo. Por ejemplo, la ley de 1934 acerca de la esterilización eugénica se instaló gracias a la participación activa del doctor Gütt (médico, alto funcionario), del jurista Falk Ruttke y del psiquiatra y genetista suizo Ernst Rüdin. Así, 400.000 alemanes fueron esterilizados entre 1934 y 1945, representando el consenso de la casi totalidad de los miembros de la comunidad médica alemana. Luego vinieron las exterminaciones planificadas de gitanos y judíos y la esterilización de mestizos, mulatas, norafricanos, indochinos, entre otros grupos. Es interesante notar que esa forma de eugenismo se basaba sobre una noción considerada como mítica de la "raza aria", también conocida como "raza nórdica" o "raza alpina". El eugenismo alemán y sus variantes suecas y estadouniden- ses no eran actos aislados de algunos perversos, sino un proceso de eliminación sistemática, basado en técnicas científicas y organizadas por la administración.

Sobre la base de tales antecedentes resulta fácil entender que el eugenismo tenga una connotación casi exclusivamente negativa. En particular, cuando tenemos a disposición las herramientas genéticas necesarias para aplicarlo. En general, el eugenismo conserva muchos detractores (en Alemania, debido al shock que provocó el eugenismo nazi, es casi imposible abordar el tema: pasó a ser una especie de tabú). En otros países el eugenismo está siempre a la orden del día cuando se trata de "mejorar" la especie humana, el individuo, o de eliminar enfermedades potenciales, genes defectuosos y otras fallas biológicas. Una de las escuelas más interesantes es la francesa, dada la enorme actividad en la materia. El eugenismo negativizante (que no contempla la libre elección) es una noción que muchos han tratado de cambiar en pos de ayudar al ser humano. Otros nunca aceptaron que el término "eugenismo" fuera asociado a una noción positiva. Está claro que la comunidad judía es la primera en oponerse a tal asociación. Así, nacieron muchas acomodaciones del término, las cuales le hicieron perder todo sentido posible (eugenismo positivo, negativo, activo, "bien entendido", nuevo, suave, benevolente, científico, humanista, entre otras variadas acepciones).

Todas las aplicaciones -o casi- del desciframiento del genoma humano son herramientas potentes que deberían permitir la práctica de un eugenismo benevolente, pero, a la vez, pueden ser utilizadas con fines muy negativos. La clonación, la corrección de genes defectuosos, la eliminación de enfermedades genéticas y/o hereditarias, la elaboración de medicamentos "personalizados", la prevención de enfermedades altamente probables, la utilización de 
embriones y de células troncales, los transplantes de órganos, los xenotransplantes y hasta los transgénicos, son técnicas aptas para participar de manera eficiente en cualquier tipo de eugenismo. La cuestión consiste en saber si es realmente útil o necesario tratar de perfeccionar tanto la especie humana. Al tratar de responder a esto estamos nuevamente frente al concepto de "ciudad utópica", que se transforma en "utopía genética" con el deseo de llegar a perfeccionar a ultranza al ser humano, transformándolo en lo que podríamos llamar el homo geneticus.

Es preciso recordar que una de las peculiaridades de la sociedad utópica(4) es la voluntad de dominio y control integral de la naturaleza y, por extensión, del ser humano. Existe, no obstante, una natural asociación entre utopía y eugenismo. Según R. Rutier, el eugenismo es consustancial a la utopía pues ambos resultan del intenso afán de perfeccionar al hombre. Desde Platón a Campanella la ciudad utópica se caracteriza por un eugenismo de estado intervencionista que pretende administrar la reproducción humana. Hoy en día, tal como lo vimos bajo la influencia de Galton durante los siglos XIX y XX, el riesgo se inicia con la tolerancia de un eugenismo individualizado y democratizado. El teatro de Aristófanes, que enjuicia la ciudad de la República de Platón, así como las "contrautopías" del siglo XX (Huxley, Bradbury, Zamiatine), mostraron el elevado peligro para el individuo de renunciar a su propia libertad a favor de una dicha colectiva, puesto que la realización de las utopías conduce al totalitarismo y al desamparo de los hombres, vale decir, hacia la exacta antítesis de sus propósitos iniciales.

Finalmente, no podríamos cerrar este capítulo sin mencionar el concepto de "ortogenie" (orthogénie), propuesto por el francés Pierre Simon, con el fin de borrar definitivamente la noción de eugenismo 3 . Según $\mathrm{Cohen}^{4}$, “...la ortogenie se refiere a los medios médicos que tienen como objetivo una reproducción voluntaria, elegida, permitiendo a las parejas dar a luz niños con buena salud, en la perspectiva de una armonía y de un bienestar familiar". Es un concepto de no coerción, fundado sobre la libertad de elección de los padres y sus deseos de tener un hijo sano. De todos modos, creemos, subyace en estas nociones de derecho a la reproducción de niños con buena salud, de armonía y de bienestar familiar -aunque sea involuntario y basado en cierta noción altamente ética de libertad y de no coerción- la misma ideación de una ciudad utópica, de una genética utópica y, por consiguiente, de un eugenismo latente y peligroso.

Conforme a estos razonamientos, podemos preguntar si es éticamente deseable mejorar lo más posible la especie humana. El debate queda abierto y promete largas controversias que podrían permitir que se apliquen las herramientas biomédicas actuales antes de tener una opinión inequívoca.

\section{Reflexión. La bioética y su lugar en las decisiones en las biociencias y biotécnicas}

La bioética emite propuestas basadas en un concilio que reúne a los representantes del pensamiento moral y que pone, teóricamente, todos los estamentos y componentes de la sociedad alrededor de la mesa. No existe para legislar y no es una ciencia, pues no se basa en el método científico, sino en un método en sí ca-

\footnotetext{
"Orto" significa derecho y "genie" deriva de genética, sin embargo, con el propósito de no referirse a la "ortogénesis", o idea según la cual los organismos vivos evolucionan en una dirección determinada estimulados por una fuerza interna, se adoptó el término "ortogenie" que engloba, a la vez, los conceptos de norma y de gen.

4 Cohen J. Eugénisme et orthogénie. Extracto de los proceedings de la jornada de estudio del 4 de marzo de 1997 sobre eugenismo y reproducción, en París, Francia.
} 
racterizado por un conjunto de herramientas prácticas y un debate permanente.

\section{Algunos factores de riesgo y peligro en las tomas de decisión}

Existen varios peligros que pueden poner en jaque a las leyes o decretos, debido al tiempo que se requiere para elaborar estos últimos. Un ejemplo es la clonación de seres humanos o el uso de embriones para la experimentación antes de que existiesen leyes que reglamentaran el uso de dichas tecnologías. A mediados de 2001, prestigiosas revistas internacionales, como Time, Wired y Focus publicaron a la clonación humana como tema principal, dedicándole la portada completa y acentuando sus reflexiones sobre la conjetura - que varios científicos sustentaron-, según la cual el primer clon humano se crearía antes del final del mismo año. Mientras muchos países no tienen ninguna ley sobre el tema, ni siquiera opiniones fundadas, otros han optado por legislaciones totalmente opuestas (por ejemplo, EE.UU., Europa y China). Este vacío deja abierta la puerta a quienes desean clonar el ser humano por razones a menudo muy cuestionables. Por ejemplo, los médicos Antinori y Zavos, que argumentaron que la decisión de clonar es únicamente médica y no ética, ya que apunta al derecho de las personas a reproducirse. A la vez, se hicieron una enorme publicidad. Otro ejemplo es el de la secta raeliana, la cual, apoyada en livianas creencias y con la ayuda de grandes respaldos económicos de fuentes desconocidas, ya está tratando de clonar humanos y se ufana de haberlo logrado hace tiempo.

También existe el peligro de la influencia de fuerzas mayores, como el libre mercado en las sociedades liberales, las que se nutren de su creciente economía y que, por lo tanto, dependen de ellas. La gran rapidez del progreso tecnológico versus la lentitud de las propuestas éticas en la elaboración de leyes y en la adaptación social constituye un factor de riesgo que pone sobre el tapete la eventual necesidad de controlar la velocidad del mismo progreso en pos de velar por la no maleficencia y la justicia. De todas maneras, se crea un dilema cuando se toma en consideración la necesidad de favorecer la velocidad del progreso como factor participativo en las economías y en el mejoramiento de la salud de los individuos.

Adicionalmente, existen reales "batallas" entre las escuelas de pensamiento (moral revelada, ética de consenso, utilitarismo, racionalismo, materialismo, entre variadas posturas) que permiten aumentar la distancia entre "lo que se dice" y "lo que se hace". A título de ejemplo, dos perspectivas totalmente opuestas: la posición católica romana y el materialismo comunista en cuanto a clonación humana y uso de embriones humanos se refiere. En ambos casos, prima el dogma: la Iglesia se sustenta en la letra de la Santa Biblia (revelada por Dios mismo y, por tanto, incuestionable) y los materialistas maoístas en el dogma de la supremacía del todo en detrimento de las partes (de los valores del sistema sobre los del individuo). Uno se opone mientras el otro acepta, afirmándose ambos en el principio de una moral de tipo “canónica” y, por ende, indiscutible.

\section{Propuestas facilitadoras del necesario concilio en la bioética relacionada con los productos de la genómica}

Las distintas interpretaciones de los pensamientos se vuelven cada vez más centrípetas en cuanto a la genómica y sus productos. La supremacía de la subjetividad ortodoxa sobre la objetividad obtenida por la observación y el debate, metaposicionados en la ética aplicada (bioética) producen discrepancias paralizantes en las propuestas morales. Creemos que un nuevo paradigma conciliador podría ser la pues- 
ta en "estado de metanoia" (es decir, con lo que está "más allá del pensamiento o del conocimiento"), enfatizando "la percepción unitaria" que se encuentra en la base de casi todas las creencias y religiones del mundo.

Otra aproximación ofrece la escuela de pensamiento llamada "trascendentalista", con influencias de Kant y el neoplatonismo, el romanticismo inglés y la filosofía hindú; movimiento ideológico que fue propio de las ex colonias inglesas independientes de los EE.UU. en la década de 1830. Ralph Waldo Emerson fue su figura principal y algunos de sus integrantes fueron Bronson Alcote, Margaret Fuller, Theodore Parker, William Channing, Henry David Thoreau, Walt Whitman, el Conde León Tolstoi y el mismo Mohandas K. Ghandi. En esencia, Emerson define su libro Naturaleza (1936)(5) como un ensayo dedicado a la ética natural, luchando arduamente contra un calvinismo predominante, fruto del racionalismo del siglo XVIII y de las ideas de la Revolución Francesa que favorecieron la doctrina en boga en la nueva América independiente.

Está claro que el trascendentalismo contiene los gérmenes del pensamiento de "estado de metanoia" antes mencionado y demuestra, a través de sus más fieles defensores y adeptos, que puede ser una propuesta unitaria y universal de ética teórica y práctica, sin oponerse y sin defender las escuelas de pensamiento en lucha, antes mencionadas. Finalmente, cabe destacar que los movimientos heterodoxos y progresistas, tanto en psicología (desde Reich $\mathrm{y}$, particularmente, desde Perls) como en filosofía, antropología y religión (acercamiento de las religiones y filosofías cristianas a las religiones y filosofías hinduistas, budistas y taoístas, tanto como a las sufíes, judías y musulmanes) han progresado en ese sentido a lo largo del siglo XX y siguen hoy en día un camino alentador hacia el unitarismo espiritual $\mathrm{y}$ humano.

\section{Conclusiones}

La sociedad "genética" que se está bosquejando no es la "ciudad utópica" de Tomás Moro, pero es un resurgimiento, una nueva forma revisada por la modernidad y los progresos de la tecnociencia.

Después de habernos extendido sobre el posible futuro de los productos de la genómica y de las dificultades y riesgos de argumentar la propuesta bioética, debido a sus debilidades intrínsecas y extrínsecas, así como de haber esbozado una vía posible de conciliación en la ética práctica que podría, eventualmente, permitir la unificación de las escuelas de pensamiento, creemos que, tal como están las cosas hoy en día, sería tal vez indispensable proponer una moratoria acerca de la finalidad de los productos de la genómica. El genoma, en su fase actual de desciframiento, no permite aún llegar a practicar el eugenismo, no permite todavía fabricar medicamentos personalizados, practicar transplantes e injertos "perfectos", entre sus variadas aplicaciones, pero sí permite ya la clonación y el uso de células embrionarias, así como clonar individuos, aunque con dificultad. Estamos a la puerta de una nueva era y estamos elaborando la ciudad utópica con todas las dificultades y los peligros que hemos expuesto. Nos parece imprescindible llegar a consensos muy amplios, tomando en consideración a todos los pueblos, países, estamentos, religiones y culturas antes de seguir en la vía que hemos emprendido. El propósito es adaptar mejor la bioética a un espíritu universal y, así, proponer soluciones viables a la humanidad. 


\section{Referencias}

1. Castells M. La era de la información: economía, sociedad y cultura. Madrid: Alianza; 1998.

2. Galton F. Eugenics: its Definition, Scope and Aims. American Journal of Sociology 1904; X(1).

3. Galton F. Hereditary Genius. London: Macmillan; 1869.

4. Bacon F. La Nouvelle Atlantide. Paris: Flammarion; 1995.

5. Emerson R. The conduct of life. Nature \& other essays. London: Dutton \& Co.; 1908.

\section{Bibliografía}

Beck U. La sociedad de riesgo. Barcelona: Paidós; 1998.

Harris J. Clones, genes, and immortality: ethics and the genetics revolutions. Oxford: Oxford University Press; 1998.

Harris M. Materialismo cultural. Madrid: Alianza; 1982.

Jonas H. El principio de la responsabilidad. Ensayo de una ética para la civilización tecnológica. Barcelona: Herder; 1995.

Lolas F. Bioética. Santiago de Chile: Editorial Universitaria; 1998.

Nussbaum M, Sunstein C, eds. Clones and clones: facts and fantasies about human cloning. New York: Norton \& Company; 1998.

Singer P. Ética práctica. Cambridge: Cambridge University press; 1995. 